\title{
Resenha: Psicologia Escolar na Atualidade: Formação, Pesquisa e Prática
}

\author{
Gisele Cristina Resende Fernandes da Silva ${ }^{1}$ \\ Universidade Federal do Amazonas
}

O presente livro, organizado por Claisy Maria Marinho-Araújo, constitui uma das mais recentes publicações do grupo de trabalho (GT) em Psicologia Escolar e Educacional da ANPEPP (Associação Nacional de Pesquisa e Pós-Graduação em Psicologia). Essa Associação é composta por grupos de trabalhos ligados às diversas áreas da Psicologia e se reúne a cada dois anos com o intuito de discutir aspectos ligados aos programas de Pós-Graduação em Psicologia no Brasil.

O grupo de trabalho Psicologia Escolar e Educacional discute questões que tangem a formação de psicólogos, os contextos de atuação e as investigações/pesquisas e avanços da área, objetivando a construção e a reflexão da psicologia escolar no Brasil às quais são posteriormente organizadas e publicadas.

Essa obra apresenta o compromisso dos autores com as necessidades de transformações socioeducativas e ético-políticas dos contextos em que há a interface da Psicologia com a Educação. As transformações são pensadas em três grandes categorias temáticas que exprimem o comprometimento desse grupo de pesquisadores: a primeira se refere à formação do psicólogo, a segunda aos fundamentos epistemológicos e a terceira a pesquisa e intervenção em Psicologia Escolar e Educacional.

A primeira temática e compromisso do grupo de trabalho em psicologia escolar e educacional se referem aos desafios e perspectivas para a formação do psicólogo escolar a partir das Diretrizes Curriculares Nacionais e os impactos das alternativas na formação profissional do psicólogo escolar. Tais reflexões favorecem uma prática inovadora que promova desenvolvimento e aprendizagem com vistas para atuações que superem a vulnerabilidade e as dificuldades que o psicólogo enfrenta quando pretende responder adequadamente às demandas sociais e educacionais.

A segunda categoria temática reflete as concepções, os fundamentos epistemológicos, filosóficos, teóricos, conceituais e metodológicos que embasam atualmente as práticas e intervenções dos psicólogos escolares e as experiências desenvolvidas, de maneira a retratar as contribuições que a área pode oferecer para aqueles que encontram e enfrentam dúvidas em sua atuação nos espaços educativos e escolares.

E a terceira temática e compromisso enfatizam as possibilidades de ampliação da formação do profissional por meio da pesquisa e da intervenção em psicologia escolar diante de compromissos com demandas sociais emergentes, como: a inclusão escolar, desde a deficiência intelectual às altas habilidades, o combate ao consumo e abuso de drogas e a atuação em contextos pouco explorados como abrigos, centros socioeducativos e ensino superior.

1 Endereço para correspondência: Av. Buriti, 3100 - Residencial Eliza Miranda - Rua 07, bloco C, apto 202 - Distrito Industrial - Manaus/ AM, CEP 69075-000. Tel.: (92) 8841-5135.Email: gcrfs@ig.com.br
Considerando tais temas emergentes na atuação do psicólogo escolar, os autores organizam o livro em três partes, totalizando doze capítulos: na primeira parte denominada Cenário da Formação em Psicologia Escolar, encontram-se dois capítulos que podem ser classificados nessa área de formação do psicólogo escolar, pois se preocupam em refletir sobre essa questão. O capítulo um é intitulado: Desafios e Perspectivas para a Psicologia Escolar com a Implantação das Diretrizes Curriculares de Alacir Villa Valle Cruces. O capítulo dois é Formando Psicólogos Escolares: Problemas, vulnerabilidade, desafios e horizontes de Raquel Souza Lobo Guzzo, Adinete Sousa da Costa e Izabella Mendes Sant'Ana.

A segunda parte do livro trata do Panorama Atual das Concepções e Práticas em Psicologia Escolar e contém quatro capítulos. O capítulo três é escrito por Marisa Maria Brito da Justa Neves e trata da Atuação dos psicólogos escolares no Distrito Federal. No capítulo quatro, Marilene Proença Rebello de Souza e Silvia Maria Cintra da Silva refletem sobre a Atuação do psicólogo na rede pública de educação frente à demanda escolar: concepções, práticas e inovações. No capítulo cinco, Marida Gonçalves Dias Facci escreve sobre a Intervenção do psicólogo na formação de professores: contribuições da psicologia histórico-cultural. E no capítulo seis a reflexão é acerca da Educação, valores e formação de professores: contribuições da psicologia escolar elaborado por Vera Lúcia Trevisan de Souza.

A terceira parte do livro é denominada Pesquisa e intervenção em psicologia escolar: ampliação de contextos, perspectivas e compromissos e contém seis capítulos. No capítulo sete, Claisy Maria Marinho-Araújo escreve sobre a Psicologia escolar no ensino superior: novos cenários de intervenção e pesquisa; o capítulo oito versa sobre o tema Explorando possibilidades: o trabalho do psicólogo na educação superior de Sônia Maria Rocha Sampaio; no capítulo nove Alexandra Ayach Anache trata do tema $O$ psicólogo escolar e o processo de escolarização de pessoas com deficiência intelectual. Denise de Souza Fleith, no capítulo dez, refelte sobre a Contribuição do psicólogo escolar para o desenvolvimento das altas habilidades; no capítulo onze, Abrigamento, narrativas infantis: a importância da psicologia escolar em contextos de abrigos é a reflexão proposta por Célia Vectore e Cíntia Carvalho; e, no capítulo doze, Herculano Ricardo Campos e Débora Karla Sampaio Alves proporcionam uma reflexão sobre o Consumo de álcool pelas adolescentes: um (novo) desafio para o psicólogo na escola.

É uma obra abrangente que aponta a necessidade de reflexão dos componentes curriculares da formação do psicólogo escolar, desde as abordagens e disciplinas teóricas, bem como, estágios supervisionados e experiências práticas oferecidas nas faculdades e universidades brasileiras.

Os autores enfatizam a necessidade de uma formação ampla para que o aluno, futuro profissional, assimile elementos 
teóricos e metodológicos sólidos construídos na graduação para sustentar sua atuação.

A proposta é que os profissionais ao atuarem nos cenários educativos assumam uma postura crítica que auxiliem na transformação social e na elaboração de políticas educacionais que favoreçam a aprendizagem e a equidade de oportunidades. Que não focalizem o trabalho apenas no aluno "culpabilizando-o" pelos insucessos e dificuldades, tampouco em suas famílias, professores e nas condições socioeconômicas; mas que possam visualizar o contexto regional no qual atuam e o panorama nacional para planejar um trabalho eficiente e que favoreça o desenvolvimento humano, a aprendizagem e uma nova realidade educativa.

Por fim, demonstra a relevância e a urgência de pesquisas na área, enfatizando o diálogo constante entre profissionais e a universidade, para que a práxis seja revista e repensada constantemente, pois esse deve ser o exercício para a construção de conhecimentos que embasam a atuação profissional. Aborda temáticas atuais na psicologia escolar, exemplificando a atuação do psicólogo em diversos contextos educacionais, com constantes mudanças e com emergentes necessidades que revelam os valores, as concepções e as preocupações da sociedade contemporânea, e, sobretudo a urgência de profissionais capacitados para atender essas demandas diversas.

\section{Referência}

Marinho-Araújo, C. M. (Ed.) (2009). Psicologia Escolar: novos cenários e contextos de pesquisa, formação e prática. Campinas: Editora Alínea.

\section{CONGRESSO BRASILEIRO DE PSICOTERAPIAS CORPORAIS}

Período: 23 de Junho - 25 Junho 2011

Local: Curitiba-PR, BR 